\section{Development of web-based combine harvester custom-hiring model for rice-wheat cropping system}

\author{
Roaf Ahmad Parray, Indra Mani, \\ Adarsh Kumar and Tapan Kumar Khura
}

ICAR-Indian Agricultural Research Institute, New Delhi 110 012, India

A web-based custom hiring model was developed to help farmers and custom-hiring service providers take decisions regarding owning/custom hiring of combine harvester for rice-wheat cropping system. It also gives the break-even acreage for owning a combine harvester along with various cost economics. The model was evaluated for two situations: situation I with own area of 100 acres and custom-hiring catchment area of 160 acres combined under rice and wheat, and situation II with own area and custom-hiring catchment area being 60 and 276 acres respectively. For situation I the model guided the user to opt for custom-hiring, while for situation II it gave a decision to own a combine harvester.

Keywords: Custom hiring, combine harvester, ricewheat cropping system, web-based model.

TIMELINESS of agricultural operations are crucial to cope with climatic variability, especially with sowing, harvesting and intercultural operations. With increasing climatic variability, timely operations alone can reduce crop losses significantly. However, farmers are often not able to complete critical operations in time for want of labour availability. Among the critical operations, harvesting is an important one, the delay of which leads to significant loss of standing crop ${ }^{1}$. This calls for promotion of appropriate agricultural machinery for performing critical agricultural operations. Although several efforts have been made in this direction in the past, there is not much improvement into the timeliness of agricultural operations. This is mostly because of the unaffordability of many machines by small farmers and difficulties in maintenance and repair. Majority of small cultivators are poor and not in a position to purchase costly machinery such as tractors, combine harvesters, etc. Due to the seasonal nature of agriculture, the farm machinery remains idle most of the time. This results in unnecessary high costs unless proper alternate use of such machinery is made in the off-season ${ }^{2}$. Lack of proper knowledge among farmers to purchase farm machinery, operate and maintain them properly leads to wrong choices, making it uneconomical and risky. In general, high initial cost often prohibits individual ownership, especially amongst small and medium farm holds. One of the most successful strategies to overcome the above difficulties is the custom hiring of

*For correspondence. (e-mail: rouf.engg@gmail.com) agricultural implements. Custom hiring allows a farmer to gain short-term control of a combine without investing a large amount of capital. There is no long-term capital investment in the machine. However, in terms of economics, the area to be custom-hired, yield, custom-hiring rate in the area, custom-hiring opportunity in the area and operating costs are some of the factors that need to be considered while deciding whether a farmer should combine and harvest his own crops, or hire a custom harvester. Unfortunately, most formers do not have the necessary information and knowledge at their disposal to help them take sound decisions regarding machinery management and other production-related activities ${ }^{3}$. A computer model for machinery selection and management may prove to be a most useful decision tool to guide farmers.

With the development of information technology, many agricultural mechanized management systems have been developed and put into practice. Wang et al. ${ }^{4}$ developed a web-based information management system of agricultural mechanization. A comprehensive programme was developed that used the mixed integer linear programming model to select agricultural machinery for multifarm systems ${ }^{5} . \mathrm{Li}^{6}$ designed a decision support system of farm machinery replacement based on the proposed models. Sahu and Raheman ${ }^{7}$ designed the decision support system of tractor equipment system matching and performance prediction using Visual Basic 6.0. Wang et $a l .{ }^{8}$ designed and developed agricultural machinery information management system using a database. ASP.NET and SQL Server 2000 were used to design and develop a decision support system by system for optimal fertilization $^{9}$. Expert decision support system was developed using system modelling method that could choose suitable tractor implement system according to different soils or operational environment ${ }^{10}$. Similarly, agricultural machinery information inquiry system of Yunnan Province, China was developed using Access ${ }^{11}$. However, a decision support system related to custom hiring of farm machines has not been reported until now. In the present study, we have developed a custom-hiring decision tool for one of the most widely used custom-hiring machines, i.e. combine harvester. This web-based application system has been developed as a decision tool to help farmers and customhiring service providers regarding the selection and use of combine harvester in rice-wheat cropping system.

The web-based application was developed using PHP language. PHP is a widely used open-source generalpurpose scripting language that is especially suited for web development and can be embedded into HTML. It is a scripting language that is well suited to server-side web development, in which case PHP generally runs on a web server. Any PHP code in a requested file is executed by the PHP runtime, usually to create dynamic web page content or dynamic images used on websites, or elsewhere. PHP code can be simply mixed with HTML code, or it can be used in combination with various templating 


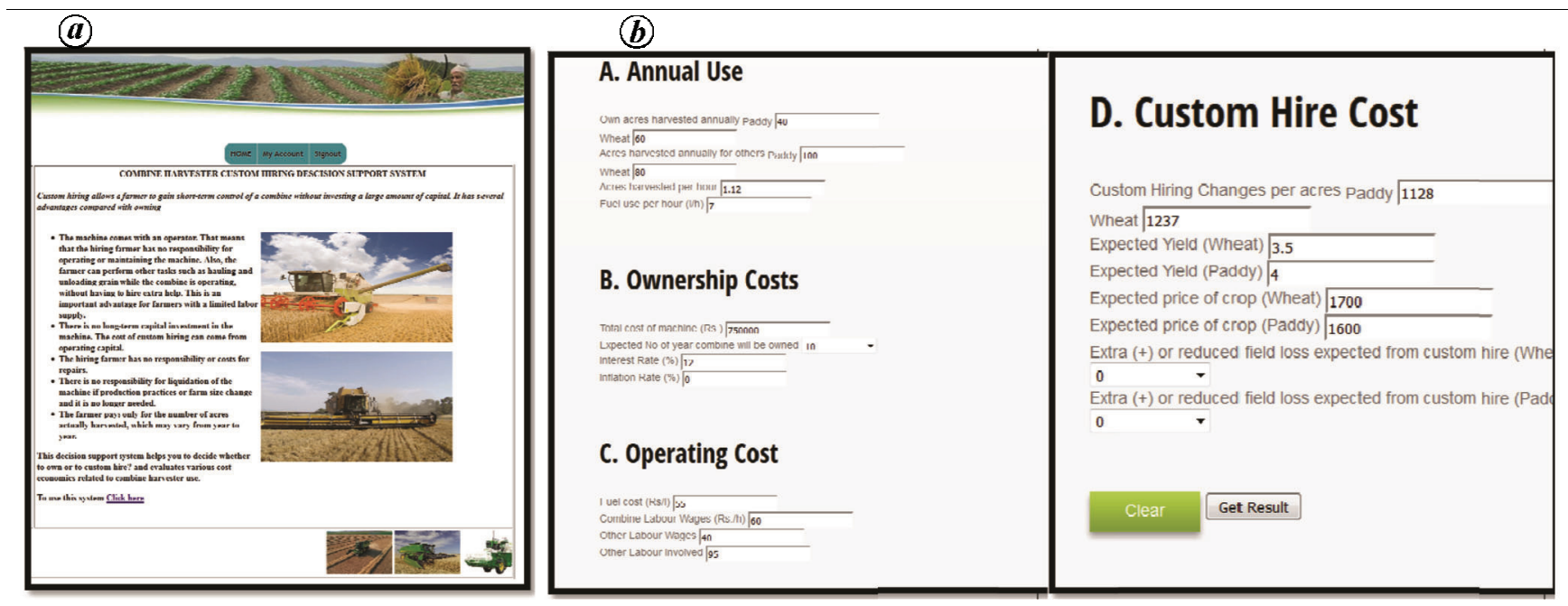

Figure 1. $\boldsymbol{a}$, Custom-hiring model interface; $\boldsymbol{b}$, Input window for the developed web system.

Table 1. Accumulated repair and maintenance costs as a percentage of actual price

\begin{tabular}{lc}
\hline $\begin{array}{l}\text { Accumulated } \\
\text { hours of use }\end{array}$ & $\begin{array}{c}\text { Repair and maintenance } \\
\text { cost }(\%)\end{array}$ \\
\hline 300 & 0 \\
600 & 1 \\
900 & 3 \\
1200 & 6 \\
1500 & 9 \\
1800 & 14 \\
2100 & 19 \\
2400 & 25 \\
2700 & 32 \\
3000 & 40 \\
\hline
\end{tabular}

engines and web frameworks. PHP code is usually processed by a PHP interpreter, which is usually implemented as a native module of the web server or a common gateway interface executable. After the PHP code is interpreted and executed, the web server sends the resulting output to its client, usually in the form of a part of the generated web page; for example, PHP code can generate the HTML code of a web page, an image, or some other data. PHP has also evolved to include a command-line interface capability and can be used in standalone graphical applications. The whole web application was developed in PHP.

PHP is specifically designed for web programing. Web development with PHP through MySQL is free to use. PHP is considered to be the best programing language for both website development and web development. The program was written for various cost calculations and based on this, a decision aid was added to the program. Figure $1 a$ and $b$ shows the interface and input page of the web-based application respectively.
The various cost calculations done based upon user input are listed as following:

A: Annual use

Own area (acre) of paddy and wheat harvested annually $A_{1}=A_{\text {op }}+A_{\text {ow }}$.

Probable area (acre) of paddy and wheat to be harvested for others $A_{2}=A_{\text {ip }}+A_{\text {iw }}$.

Total area (acre) harvested $A_{3}=A_{1}+A_{2}$

Area (acre) harvested per hour $=A_{4}$

Total annual hours of use $A_{5}=A_{3} / A_{4}$

Fuel use per acre $(1 /$ acre $)=A_{6}$

Annual fuel use (1) $A_{7}=A_{3} \times A_{6}$

where $A_{\text {op }}$ is the own area (acres) of paddy; $A_{\text {ow }}$ the own area (acres) of wheat; $A_{\text {ip }}$ the area (acres) of paddy available for custom hiring; $A_{\text {iw }}$ the area (acres) of wheat available for custom-hiring.

\section{B: Ownership costs}

Total purchase cost of combine $=B_{1}$

Expected number of years the combine will be owned (life) $=B_{2}$

Salvage value after $B_{2}$ years $B_{3}=0.1 \times B_{1}$

Annual depreciation $B_{4}=B_{3} / B_{2}$

Interest rate $(\%)=B_{5}$

Annual interest rate $B_{6}=B_{1} \times B_{5}$

Annual charge for housing and insurance $B_{7}=1 \% \times B_{1}$

Total annual ownership cost $B_{8}=B_{4}+B_{6}+B_{7}$.

\section{C: Operating costs}

Annual fuel cost $C_{1}=A_{7} \times$ fuel cost (Rs/l)

Annual lubrication cost $C_{2}=15 \% \times C_{1}$

Estimated accumulated hours of use after $B_{2}$ years: $C_{3}=B_{2} \times A_{7}$

Repair cost $\%$ from Table 1 for $C_{3}$ hours $=\mathrm{C}_{4}$ 
Table 2. Input-output of custom-hiring model for situation I

\begin{tabular}{lcc}
\hline Input area (acre) & Paddy & Wheat \\
Own area & 40 & 60 \\
Custom area & 100 & 80 \\
& & Rs 168,750 \\
Model output & Rs 175,253 \\
Annual fixed cost & Rs 113,140 \\
Annual operating cost & Rs 193,760 \\
Custom-hiring cost & Rs 344,003 \\
Custom-hiring income & Rs 150,243 \\
Total annual cost & Better to custom hire \\
Net cost & Rs 1131 \\
Decision & Rs 1076 \\
Average custom-hiring cost per acre & 173 \\
Average custom-hiring income per acre & 1073 \\
Minimum area (acre) of own crops needed to break even on combine ownership & 262.3 \\
$\quad$ (assuming custom-hiring income constant) & \\
Minimum area (acre) of custom work needed to break even on combine ownership & (assuming own crops constant)
\end{tabular}

Annual repair cost $C_{5}=B_{2} \times C_{4} / B_{2}$

Combine labour value $C_{6}=A_{5} \times$ labour wages $(\mathrm{Rs} / \mathrm{h})$

Other labour involved $C_{7}=$ Labour hours $\times$ labour wages (Rs/h)

Total annual operating cost $C_{8}=C_{1}+C_{2}+C_{5}+C_{6}+C_{8}$

D: Custom-hiring cost

Custom-hiring charges per acre for paddy $D_{1}=C_{\mathrm{p}}$

Custom-hiring charges per acre for paddy $D_{2}=C_{\mathrm{w}}$

Custom-hiring cost per year $D_{3}=A_{\mathrm{op}} \times C_{\mathrm{p}}+A_{\mathrm{o}} \times C_{\mathrm{w}}$

Extra (+) or reduced (-) field loss from custom hiring (\%) of paddy $=\mathrm{ER}_{\mathrm{p}}$.

Extra $(+)$ or reduced (-) field loss from custom hire (\%) of wheat $=\mathrm{ER}_{\mathrm{w}}$.

Expected yield of paddy $(q /$ acre $)=Y_{\mathrm{p}}$

Expected yield of wheat $(q /$ acre $)=Y_{\mathrm{w}}$

Expected price of paddy $(\mathrm{Rs} / \mathrm{q})=D_{8}$

Expected price of wheat $(\mathrm{Rs} / q)=D_{9}$

Change in value of field loss $D_{10}=\left(A_{\mathrm{op}} \times \mathrm{ER}_{\mathrm{p}} \times\right.$ $\left.Y_{\mathrm{p}} \times D_{8}\right)+\left(A_{\mathrm{o}} \times \mathrm{ER}_{\mathrm{w}} \times Y_{\mathrm{w}} \times D_{9}\right)$

Value of other labour involved $D_{11}=$ labour hours $\times$ labour wages $(\mathrm{Rs} / \mathrm{h})$

Total annual cost for custom-hiring $D_{12}=D_{3}+D_{10}+D_{11}$

E: Custom-hiring income received

Custom-hiring charges per acre for paddy $E_{1}=C_{\text {ip }}$

Custom-hiring charges (income) per acre for wheat $E_{2}=C_{\text {iw }}$

Annual custom-hiring income $E_{3}=A_{\text {op }} \times C_{\text {ip }}+A_{\text {ow }} \times C_{\text {iw }}$

\section{F: Summary}

Total annual ownership cost $F_{1}=B_{8}$

Total annual operating cost $F_{2}=C_{8}$

Total annual cost $F_{3}=B_{8}+C_{8}$

Total annual custom-hiring income $F_{4}=E_{3}$

Net cost for ownership $F_{5}=F_{3}-F_{4}$

Total custom-hiring cost $F_{6}=E_{3}$
Decision: If $F_{6}>F_{5}$, it is cheaper to own than to customhire.

If $F_{5}>F_{6}$, it is cheaper to custom hire than to own.

G: Break-even analysis

Average custom-hiring cost per acre $=D_{12} / A_{1}$

Average operating cost per acre $=C_{8} / A_{3}$

Average custom-hiring income per acre $=E_{2} / A_{2}$

Added income per acre of custom work done $=G_{3}-G_{2}$

Minimum area (acre) of own crops needed to break even on combine ownership (assuming custom-hiring income constant $)=\left[F_{1}-\left(A_{2} * G_{4}\right)\right] /\left(G_{1}-G_{2}\right)$

Minimum area (acre) of custom work needed to break even on combine ownership (assuming area under own crops constant $)=\left[\left(A_{1} * G_{2}\right)+F_{1}-F_{6}\right] / G_{4}$.

Assumptions:

Area harvested per hour $=1.12$ (acres)

Cost of combine harvester $=750,000$

Interest rate $=12 \%$

Life of combine $=10$ years

Lubrication cost $=15 \%$ of fuel cost

Fuel consumption $=71 / \mathrm{h}$

Salvage value $=10 \%$ of initial cost.

The web-based custom-hiring model was evaluated for different situations. Table 2 shows the results obtained for an input of own area of 40 and 60 acres and expected catchment area of 100 and 80 acres under rice and wheat respectively, to be available for custom-hiring. The total annual cost found to be Rs 344,003 and total customhiring income is Rs 193,760, indicating a net cost of Rs 150,243 . On the other hand, the total cost involved in custom-hiring own area is 113,140 .

Since custom-hiring cost is less than the net cost, the decision support system suggests that it is better to custom hire than to own a combine harvester. For owning the 


\section{RESEARCH COMMUNICATIONS}

Table 3. Input-output of custom hiring model for situation II

\begin{tabular}{lcc}
\hline Input area (acre) & Paddy & Wheat \\
Own area & 30 & 30 \\
Custom area & 138 & 138 \\
& Rs 168,750 \\
Model output & Rs 197,568 \\
Annual fixed cost & Rs 68,750 \\
Annual operating cost & Rs 298,770 \\
Custom-hiring cost & Rs 366,318 \\
Custom-hiring income & Rs 67,548 \\
Total annual cost & Better to own \\
Net cost & Rs 1146 \\
Decision & Rs 1083 \\
Average custom-hiring cost per acre & Rs 495 \\
Average custom-hiring income per acre & \\
Added income per acre of custom work done & 57.84 \\
Minimum area (acre) of own crops needed to break even on combine ownership $\quad$ (assuming custom hire income constant) & 273.57 \\
Minimum area (acre) of custom work needed to break even on combine ownership & (assuming own crops constant) &
\end{tabular}

combine, with constant area (acre) of custom-hiring, the minimum own area needed is 173.3 acres, i.e. additional 73.3 acres own area to justify the owning of a combine harvester. For this situation in which the own area (acre) constant, there is a need of total 262.3 acres expected custom-hiring catchment area, indicating that an additional custom-hiring area of 82.3 acres will justify the owning of a combine.

The results shown in Table 3 are for the situation with a fixed own area of 30 acres each under rice and wheat, and fixed area expected to be available for custom hiring of 138 acres each under rice and wheat. The output of the web-based custom-hiring model depicts that the total annual cost will be Rs 366,318 and total custom-hiring income will be Rs 298,770. The net cost of Rs 67,548 being less than the custom-hiring cost of Rs 68,750 suggests that it is better to own the combine harvester than opt for custom-hiring of harvesting operation for rice and wheat.

There will be an added income of Rs 495 per acre of custom work done. The minimum own area to justify owning of combine harvester is 58 acres, while the already available own area is 60 acres. Similarly, the minimum catchment area of custom acres to justify owning is 274 acres, being lesser than the available acres by a margin of 2 acres.

Thus, the web-based application system is a useful tool to help farmers decide whether to own a combine or opt for custom-hiring of harvesting operation. It also helps the custom-hiring service providers to decide the minimum catchment area required for custom-hiring to be profitable. The model gives detailed account of various cost economics involved in combine harvesting of ricewheat cropping system.

1. Mehta, C. R., Chandel, N. S., Senthikumar, T. and Singh, K. K., Trends of agricultural mechanization in India. UN CSAM Policy Brief, 2014, 1-16.
2. Sukhpal, S., Kingra, H. S. and Sangeet, A., Custom-hiring services of farm machinery in Punjab: impact and policies. Indian Res. J. Extn. Educ., 2013, 13(2), 33-44.

3. Iqbal, M. A., Asif, I., Afzal, S., Akbar, N., Nadeem, A. R. and Zaman, H. K., In Pakistan, agricultural mechanization status and future prospects. Am.-Eur. J. Agric. Environ. Sci., 2015, 15(1), $122-128$.

4. Wang, Y., Yang, F. and Yan, Z., Design and development of decision support system for equipping farm machines. $J N W, 9(6)$, $1648-1655$.

5. Camarena, E. A., Gracia, C. and Cabrera, J. M., A mixed integer linear programming machinery selection model for multifarm systems. Biosystems Eng., 2004, 87(2), 145-154.

6. Li, M., Design Theory and Application of Agricultural Machinery System Optimization, Northeast Agricultural University, 2009.

7. Sahu, R. K. and Raheman, H., A decision support system on matching and field performance prediction of tractor implement system. Comput. Sele. Agric., 2008, 60, 76-86.

8. Wang, C., Shao, L., Liu, H. and Zhu, J., Design of agricultural machinery management information system total program in Tongcheng, Anhui Agric. Sci. Bull., 2008, 8, 14-16.

9. Wang, J. and He, J., The design and implementation of decision support system for integrated optimal fertilization. Math. Comput. Modell., 2011, 54, 1167-1174.

10. Mehta, C. R., Singh, K. and Selvan, M. M., A decision support system for selection of tractor-implement system used on Indian farms. J. Terramec., 2011, 48, 65-73.

11. Ning, W. and Kuang, Y., Development of Yunnan agricultural information retrieval system. J. Agric. Mech. Res., 2012, 1, $203-$ 206

Received 17 September 2015; revised accepted 17 September 2018

doi: $10.18520 / \mathrm{cs} / \mathrm{v} 116 / \mathrm{i} 1 / 108-111$ 